\title{
Rise of superficial mycoses: A clinicoepidemiological study among the patients attending tertiary health care centre in north India
}

\author{
Suresh Ahirwar ${ }^{1}$, Vikramjeet Singh ${ }^{2}$, Manodeep Sen ${ }^{3}$, Vineeta Mittal ${ }^{4}$, Anupam Das ${ }^{5, *}$ \\ ${ }^{1}$ Consultant Dermatologist, Dept. of Dermatology, Dr. Ram Manohar Lohia Combined Hospital, Lucknow, Uttar Pradesh, ${ }^{2}$ Senior \\ Resident, ${ }^{3}$ Professor, ${ }^{4}$ Professor, ${ }^{5}$ Associate Professor, Dept. of Microbiology, Dr. Ram Manohar Lohia Institute of Medical \\ Sciences, Lucknow, Uttar Pradesh, India
}

*Corresponding Author:

Email: dranupam06@yahoo.co.in

Received: $18^{\text {th }}$ May, 2018

Accepted: $14^{\text {th }}$ June, 2018

\begin{abstract}
Introduction: Superficial mycoses refer to the disease of skin, hair and nail caused by fungi, are a serious problem due to deficient sanitation and education. This group includes dermatophytoses, non dermatophytic molds and Candida spp. Microscopic detection of fungal elements using wet mount preparation of $10 \%$ and $40 \%$ potassium hydroxide (KOH) is a rapid and precise tool for laboratory diagnosis.

Objectives: This retrospective study was conducted to evaluate the sensitivity of wet preparation direct microscopy using potassium hydroxide for early detection of fungal elements from various clinical specimens and thereby helping the clinicians in initiating the appropriate antifungal treatments.

Materials and Methods: All clinical specimen like skin and nail scrapping from patients suspected of superficial mycoses were subjected to KOH examination for screening and detection and positive samples were cultured on SDA (Sabouraud's Dextrose Agar) medium for identification.

Results: A total of 5734 samples of clinically suspected patients of superficial mycoses attended the tertiary care teaching hospital between September 2013 and August 2017 were included. 3165 patients (55\%) were found to be positive by KOH examination. In the present study the most common clinical type was tinea cruris $(74.3 \%)$ followed by tinea corporis $(22.6 \%)$ in the patients attending tertiary health care centre.

Conclusion: Clinical finding and wet mount with $\mathrm{KOH}$ can be believed upon as the single most important rapid and sensitive tool for early diagnosis of superficial mycoses. Since there is a high incidence of superficial mycoses in rural people coming to the tertiary heath care facilities therefore preventive and early screening measures are need of hours.
\end{abstract}

Keywords: Potassium hydroxide preparation, Superficial mycoses, Tinea spp.

\section{Introduction}

Superficial mycoses refers to fungal infection of keratinised tissues mainly stratum corneum of skin and its appendages nails and hair caused by dermatophytes and occasionally non dermatophytic molds and Candida spp. The environmental factors including temperature and humidity in tropical countries like India are favourable for fungal growth over skin and its appendages. ${ }^{1}$ The socio-demographic factors like poverty, overcrowding, poor personal hygiene are also prevalent in India. The dermatophytoses are for the most part called tinea. Tinea is a Latin word and referred to ring worm. In light of their genera, dermatophytes can be arranged into three gatherings: Trichophyton (which causes diseases on skin, hair, and nails), epidermophyton (which causes diseases on skin and nails), and microsporum (which causes diseases on skin and hair). The human beings get infected either by direct transmission of these organisms from the contact of infected individual or animals or indirect contact of infected materials like exfoliated skin, hair, clothing, furniture, bed linen, towels etc. ${ }^{2}$ These lesions are usually in the irregular ring form itchy fissures and central clearing. However, the precise levels of the magnitude of the problems are not known.
The present study was attempted to survey the clinico-epidemiological profile of superficial mycoses infection to distinguish the types of fungi and to compare the clinical finding and finding of $\mathrm{KOH}$ preparation. There is an ascent in the quantity of immunosuppressed patients at an exceptional pace, the administration of dermatophytoses would be a distinct test to humankind in the years to come.

\section{Materials and Methods}

This study period was of four years from September 2013 to August 2017 and it was conducted in the Department of Microbiology at tertiary care super-speciality centre in Lucknow. All the clinically suspected superficial mycoses patients were subjected to $\mathrm{KOH}$ mount microscopy and detection by culture methods. The clinical specimens included were skin scales, hair and nails in cases of superficial mycoses.

Microscopic Examination and Culture Study: After taking detailed history of lesions and patients hygiene, clinical examination was conducted. Samples were subjected to culture study only after positivity in $\mathrm{KOH}$ smear examination. The scraping skin sites were cleaned aseptically by $70 \%$ ethanol. The ring lesions and skin scales were scraped off and collected on a 
sterile paper with help of scalpel blunt end. On a clean grease free slide direct microscopic examination using $10 \%$ potassium hydroxide $(\mathrm{KOH})$ wet mount for the specimens of skin scales, while $40 \% \mathrm{KOH}$ for hair and nail specimens was conducted. The culture was performed in sabouraud dextrose agar (SDA) media and dermatophyte test media (DTM). The culture tubes were incubated at $25^{\circ} \mathrm{C}$ and the culture growth was observed. However, the tubes were discarded only after four weeks in the absence of growth.

The dermatophytes were characterised by their appearnce macroscopically and microscopically. In the present study, macroscopically we included duration of growth (number of days), surface morphology (wooly, cottony, velvety etc) and pigment production. Microscopically fungal growth was observed using lactophenol cotton blue stain. The nature of macroconidia and microconidia formation differentiate various genera and species of fungal organisms responsible for superficial mycoses.

\section{Results}

The present study for isolation, identification and clinicomycologial study of dermatophytes was done on 5734 clinically suspected cases of superficial mycoses. Among total samples, 3165 samples were positive on $\mathrm{KOH}$ microscopy. During the four years (September 2013 - August 2017) of study period, a prominent rise in the total number of cases leading to enhanced detection of superficial mycoses as shown in Fig. 1.
Male preponderance was observed $(92.6 \%)$ in the age group of 21-30 years (24.7\%) whereas women constituted only $7.4 \%$ of the clinically suspected cases. The current study found that incidence of superficial mycoses was higher proportion in male patients 2942 (93\%) than females $223(7 \%)$ among 3165 positive cases (Table 1). This study showed statistically significant sex wise distribution of superficial mycoses $(\mathrm{P}<0.001)$.

In this study (Table 2), the age group of 21-40 years $(59.4 \%)$ is most commonly involved followed by $0-20$ years $(30.4 \%)$. The majority of the patients suffering from superficial mycoses belong to the low socioeconomic status and rural area. In this study, the maximum cases were seen in the summer months of April to September. Fewer cases occurred during the winter months.

Most of the positive specimens were received from skin lesions 2942 (93\%) as shown in Table 3. These lesions usually presents in the form of itchy, ring like lesions with redness and irregular fissured borders with a cleared central area. Nail lesions were second most common site in this retrospective study 223 cases (7\%). There was male predominance in the lesions of skin and nail infections. In the present study it was observed that most of patients coming to Dermatology department presented with Tinea cruris $(51 \%)$, Tinea corporis $(38 \%)$, Tinea pedis $(4.3 \%)$, Tinea unguium $(2.6 \%)$, Tinea manuum (1.8\%) and other lesions.

Table 1: Sex- wise distribution of clinically suspected superficial mycoses patients

\begin{tabular}{|l|c|c|c|c|}
\hline \multirow{2}{*}{ Year } & \multicolumn{2}{|c|}{ Male } & \multicolumn{2}{c|}{ Female } \\
\cline { 2 - 5 } & Total Cases & Positive Cases (\%) & Total Cases & Positive Cases (\%) \\
\hline $2013-14$ & 254 & $111(43.7 \%)$ & 34 & $10(29.4 \%)$ \\
\hline $2014-15$ & 1018 & $521(51.2 \%)$ & 104 & $33(31.7 \%)$ \\
\hline $2015-16$ & 1579 & $869(55 \%)$ & 153 & $67(43.8 \%)$ \\
\hline $2016-17$ & 2391 & $1441(60.3 \%)$ & 201 & $113(56.2 \%)$ \\
\hline Total & 5242 & $2942(56 \%)$ & 492 & $223(45 \%)$ \\
\hline
\end{tabular}

Table 2: Age- wise distribution of clinically suspected superficial mycoses patients from 2013 to 2017

\begin{tabular}{|c|c|c|c|c|c|c|c|c|}
\hline \multirow[b]{2}{*}{ Year } & \multicolumn{2}{|c|}{ 0-20 Years } & \multicolumn{2}{|c|}{ 21-40 Years } & \multicolumn{2}{|c|}{ 41-60 Years } & \multicolumn{2}{|c|}{ Above 60 Years } \\
\hline & $\begin{array}{l}\text { Total } \\
\text { Cases }\end{array}$ & Positive & $\begin{array}{l}\text { Total } \\
\text { Cases }\end{array}$ & Positive & $\begin{array}{l}\text { Total } \\
\text { Cases }\end{array}$ & Positive & $\begin{array}{l}\text { Total } \\
\text { Cases }\end{array}$ & Positive \\
\hline 2013-14 & 94 & $47(50 \%)$ & 108 & $68(63 \%)$ & 79 & $06(7.5 \%)$ & 07 & 00 \\
\hline $2014-15$ & 355 & $190(53.5 \%)$ & 498 & $337(67.7 \%)$ & 163 & $19(11.6 \%)$ & 106 & $08(7.5 \%)$ \\
\hline $2015-16$ & 596 & $333(55.9 \%)$ & 703 & $545(77.5 \%)$ & 239 & $46(19.2 \%)$ & 194 & $12(6.2 \%)$ \\
\hline 2016-17 & 700 & 475 (67.9) & 1152 & $961(83.4 \%)$ & 477 & $89(18.7 \%)$ & 263 & $29(11 \%)$ \\
\hline Total & 1745 & $1045(59.9 \%)$ & 2461 & $1911(77.6 \%)$ & 958 & $160(16.7 \%)$ & 570 & $49(8.6 \%)$ \\
\hline
\end{tabular}

Table 3: Specimen- wise distribution of clinically suspected superficial mycoses patients

\begin{tabular}{|l|c|c|c|c|}
\hline \multirow{2}{*}{ Year } & \multicolumn{2}{|c|}{ Skin } & \multicolumn{2}{c|}{ Nail } \\
\cline { 2 - 5 } & Total Cases & Positive Cases (\%) & Total Cases & Positive Cases (\%) \\
\hline $2013-14$ & 254 & $111(43.7 \%)$ & 34 & $10(29.4 \%)$ \\
\hline $2014-15$ & 1018 & $521(51.2 \%)$ & 104 & $33(31.7 \%)$ \\
\hline $2015-16$ & 1579 & $869(55 \%)$ & 153 & $67(43.8 \%)$ \\
\hline $2016-17$ & 2391 & $1441(60.3 \%)$ & 201 & $113(56.2 \%)$ \\
\hline Total & 5242 & $2942(56 \%)$ & 492 & $223(45 \%)$ \\
\hline
\end{tabular}




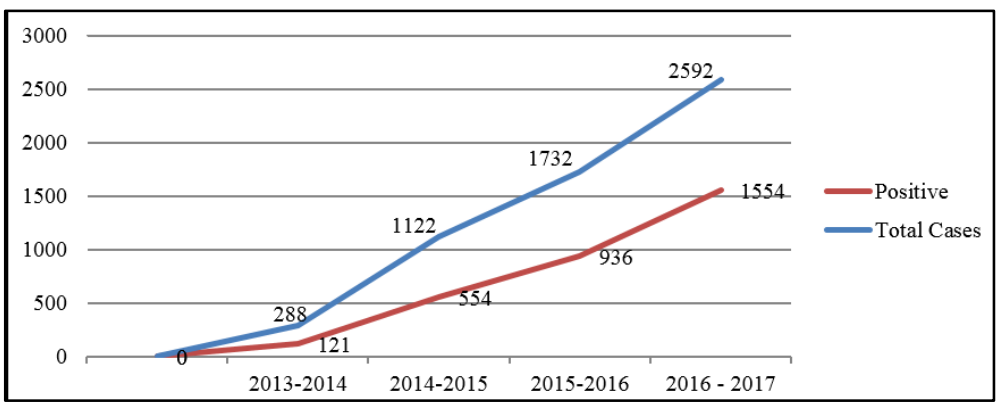

Fig. 1: Rise in the incidence of superficial mycoses in last 4 years

\section{Discussion}

The present study was conducted in tertiary health care super-speciality institute of North India. The presence of hot and humid climate along with poor hygiene in low socioeconomic status in this region of North India is more favorable for the development of superficial mycoses. In this retrospective study of four years more than 3000 cases of dermatophytic infections were diagnosed and the following clinical forms were observed: tinea corporis, tinea cruris, tinea manuum, tinea pedis and others. As regards to the incidence of superficial mycoses in different age group, maximum number of cases was observed in 21 to 40 years of age group (59.4\%). This finding is consistent with the observations of Bindu et al (2002), Peerapur et al (2004) and Singh et al (2003). ${ }^{3-5}$ Dermatophytosis was more predominantly seen in male population when compared to females. The involvement of male population in maximum outdoor activities predisposes them to increase risk of dermatophyte infection from environmental exposure and increase sweat production. This findings was in accordance with the study done by Sentamilselvi et al, Amin et al., and Singh et al. ${ }^{5-7}$ However, contrary to the present study, Belurkar et al ${ }^{9}$ reported female preponderance of above 30 years age group. Furthermore, due to the prevailing social stigma in the rural population of India, non-reporting of female patients to hospitals lead to lower incidence in females.

Among the various clinical types, incidence was highest in tinea cruris (59\%) followed by tinea corporis (38\%). This finding in the present study is consistent with the study of Bindu et al. and other studies from India, which have also observed the same pattern of dermatophytosis. ${ }^{6-8}$ In the studies conducted by Sardari et $\mathrm{al}^{9}$ and Verma et a $1^{10}$ it has been observed that tine cruris is the most common clinically presenting dermatophytosis. In the present study conducted tinea corporis was more commonly presented in comparison with tinea cruris cases. In another hospital based study of superficial mycosis from north-east India, ${ }^{11}$ it was found that tinea pedis $(29.2 \%)$ as the most common dermatophytosis followed by tinea cruris $(26.2 \%)$, which differ from other studies of India. There was absence of tinea capitis case in this study, thereby confirming its low incidence, which is consistent with the observations of study by Mehta et al. ${ }^{12}$ However, this observation is not in accordance with the study done in Kolkata where the most common dermatophytic infection in children was tinea capitis. ${ }^{13}$ In the present study, it was possible to demonstrate fungi on direct microscopy with $\mathrm{KOH}$ in majority of cases but overall positivity by culture was low as noticed in other studies. ${ }^{3,14}$ However, the findings in our study was not in accordance with the study of Belukar et $\mathrm{al}^{8}{ }^{8}$ which showed culture positivity of $71 \%$, which was significantly higher than other studies in different parts of India.

\section{Conclusion}

The present study emphasize that $\mathrm{KOH}$ preparation for superficial mycoses is a very simple, rapid and cost effective laboratory method with high diagnostic sensitivity. Further, $\mathrm{KOH}$ mount preparation has been observed to be dependable for making decisions in the empirical treatment of routine superficial mycoses.

\section{References}

1. Weitzman I, Summerbell RC. The Dermatophytes. Clin Microbiol Rev. 1995:240-259.

2. Koneman EW, Allen SD, Janda WM, Schreekberger PC, Winn WC. Mycology. In: Koneman EW, Allen SD, Janda WM, Schreekberger PC, Winn WC, editors. Colour Atlas and Textbook of Microbiology. JB Lippincott Co., Philadelphia, 2006. p. 1151-243.

3. Bindu V, Pavithran K. Clinico-Mycological study of dermatophytosis in Calicut. Indian J Dermatol Venereol Leprol. 2002;68:259-61.

4. Peerapur BV, Inamdar AC, Pushpa PV, Srikant B. Clinico Mycological Study of Dermatophytosis in Bijapur. Indian J Dermatol Venerol Leprol. 2004;22:273-74.

5. Singh S, Beena PM. Profile of Dermatophyte infection in Baroda. Indian J Dermatol Venerol Leprol. 2003;69:281-3.

6. Sentamilselvi G, Kamalam A, Ajithadas K, Janaki C, Thambiah AS. Scenario of chronic dermatophytosis: An Indian study. Mycopathologia. 1997;140:129-35.

7. Amin AG, Shah HS. Dermatophytosis. Indian J Dermatol. 1973;19:22-7.

8. Belukar DD, Barmi RN, Karthikeyan S, Vadhavkar RS. A Mycological study dermatophytosis in Thane. Bombay Hosp J. 2004;46:2

9. Sardari L, Sambhashiva RR, dandapani R. clinico mycological study of dermatophytes in a coastal area. Indian J Dermatol Venereol Leprol. 1983;49:2:71-5.

10. Verma BS, Vaishnav VP, Bhat RP. A study of dermatophytosis. Indian J dermatol Venerol Leprol. 1970;36:182. 
11. Grover SC, Roy PC. Clinicomycological profile of superficial mycosis in a hospital in North East India. Medical Journal Armed Forces India. 2003;59:114-16.

12. Mehta JP, Deodhar KP. A study of dermatophytes in Bombay. Indian J Pathol Microbiol. 1977;20:23-31.

13. Barbhuiya JN, Das SK, Ghosh A, Dey SK, Lahiri A. Clinico mycological study of superficial fungal infection in children in an Urban clinic in Kolkata. Indian J Dermatol. 2002;47:221-3.

14. Patwardhan N, Dave R. Dermatophytosis in and around Aurangabad. Indian J Pathol Microbiol. 1999;42:455-62.

How to cite this article: Ahirwar S, Singh V, Sen M, Mittal V, Das A. Rise of superficial mycoses: A clinicoepidemiological study among the patients attending tertiary health care centre in north India. Indian $\mathbf{J}$ Microbiol Res. 2018;5(3):303-306. 